Titulo do Trabalho

\title{
DESTINAÇÃO DO LIXO DOMÉSTICO E AGRÍCOLA EM PROPRIEDADES RURAIS DO MUNICÍPIO DE CASTILHO-SP
}

Nome do Autor (a) Principal

\section{Aparecida Brunetti Arante de Souza}

Nome (s) do Coautor (a) (s)

Sérgio Luís de Carvalho ${ }^{1}$; Elizete Aparecida Checon Freitas Lima²

Nome (s) do Orientador (a) (s)

Sérgio Luís de Carvalho

Aparecida Brunetti Arante de Souza

Instituição ou Empresa

Universidade Estadual Paulista "Júlio de Mesquita Filho"

Faculdade de Engenharia Campus de Ilha Solteira

Instituição (s) de Fomento

Universidade Estadual Paulista "Júlio de Mesquita Filho"

Faculdade de Engenharia Campus de Ilha Solteira

E-mail de contato

aparecidabrunetti@yahoo.com.br

Palavras-chave

Percepção ambiental. Descarte. Resíduos.

\footnotetext{
${ }^{1}$ Doutor em Ecologia pela Universidade de Campinas/UNICAMP, Brasil. Professor Adjunto na Faculdade de Engenharia de llha Solteira (UNESP). E-mail: sergicar@bio.feis.unesp.br.

2 Doutora em Ecologia de Recursos Naturais pela Universidade Federal de São Carlos/UFSCAR, Brasil. Professora Assistente Doutora na Faculdade de Engenharia de Ilha Solteira (UNESP). E-mail: eacflima@bio.feis.unesp.br.
} 


\section{INTRODUÇÃO}

No ecossistema rural pode-se observar que o conjunto de atividades agropecuárias é responsável por mudanças no ambiente, no qual existe um processo de importação energética em forma de fertilizantes químicos; combustível para movimentação de equipamentos para preparo do solo, plantio e colheita; bombeamento d'água para irrigação de culturas; transporte de insumos para a área de produção e de produtos para a área de consumo; importação biológica com a utilização de espécies vegetais e animais de outras regiões, inclusive em sistemas de monocultura; retirada de vegetação primitiva para implantação das áreas de agricultura ou pastagem para pecuária. (PHILIPPI JR e MALHEIROS, 2011).

Impulsionadas pela demanda de produtos e serviços no meio rural resultante da exploração vegetal e animal, as propriedades passam a produzir resíduos continuamente. A importação de recursos dos centros urbanos faz com que se aumentem os resíduos produzidos, uma vez que são adquiridos materiais orgânicos de fácil aproveitamento e descarte, porém há uma quantidade de material reciclável cuja disposição final torna-se relevante.

A destinação do lixo torna-se um inconveniente, pois o proprietário é impelido a fazê-la na respectiva área onde reside e produz, gerando poluição e muitas vezes adotando práticas inadequadas na disposição final dos resíduos. Acrescenta-se, ainda, que o serviço público de coleta de lixo nas áreas rurais é ainda limitado no país (Dornfeld et al. 2013), ficando com o proprietário rural, a responsabilidade pelo gerenciamento correto dos resíduos sólidos em sua propriedade.

O presente trabalho apresenta a situação da destinação dos resíduos sólidos em propriedades rurais localizadas em dois assentamentos rurais no Município de Castilho, SP. As informações geradas nesse trabalho podem ser utilizadas como subsídios para a elaboração do plano de resíduos sólidos do município, bem como para embasar programas de educação ambiental na comunidade.

\section{OBJETIVO GERAL}


- Avaliar a situação da destinação dos resíduos sólidos em propriedades rurais, localizadas no Município de Castilho, SP.

\section{OBJETIVOS ESPECÍFICOS}

- Quantificar as formas de destinação do lixo doméstico e agrícola das propriedades rurais estudadas.

\section{METODOLOGIA}

\section{Caracterização da área de estudo}

Castilho localiza-se a uma latitude $20^{\circ} 52^{\prime} 20^{\prime \prime}$ sul e a uma longitude $51^{\circ} 29^{\prime} 15^{\prime \prime}$ oeste, na mesorregião de Araçatuba (SP). A população do município é de 18006 habitantes, distribuídos numa área de $1062,5 \mathrm{Km}^{2}$. Seu relevo apresenta altitude de $365 \mathrm{~m}$ e está a $642 \mathrm{~km}$ de distância da capital.

Possui clima seco e temperado, com temperaturas médias e inverno estável. Suas superfícies planas possuem solo arenoso de alta fertilidade, viabilizando o manejo das terras. A hidrografia apresenta forte importância para o município, que é considerado o "paraíso do pescador", banhado pelos rios Aguapeí, Paraná e Tietê, sendo estes últimos navegáveis. Sua produção agrícola é baseada na pecuária leiteira e de corte e na agricultura com cultivo de cereais, leguminosas, oleaginosas, extração vegetal e marcada ainda pelo setor sucroalcooleiro. 


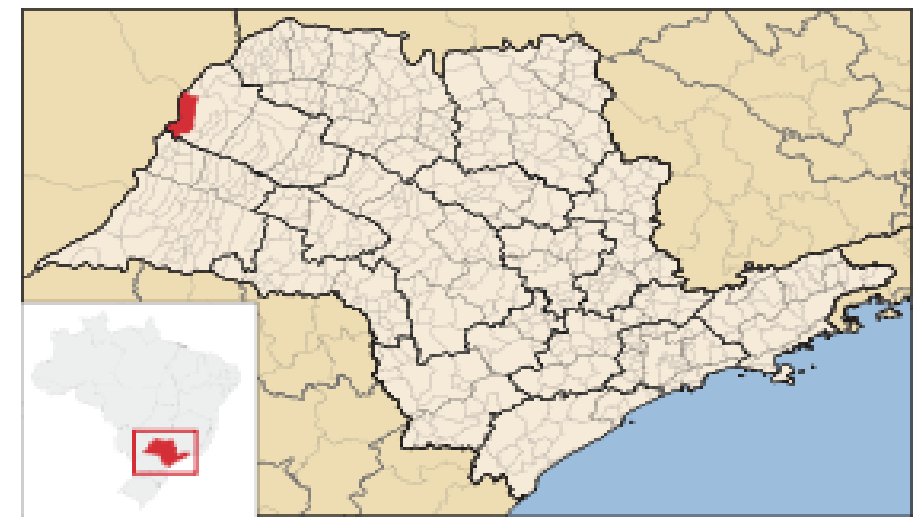

Figura 1. Localização de Castilho no estado de São Paulo.

\section{Procedimentos metodológicos}

O presente trabalho foi realizado em propriedades rurais do município de Castilho- SP, utilizando-se de um questionário baseado em Machado (1982) e Martins et al. (2005), com 26 questões contendo quadros com alternativas diversas de respostas e perguntas abertas. Os quadros de perguntas englobam a composição familiar e escolaridade; fonte de renda monetária; uso do solo; exploração vegetal e animal; tecnologias e canais de comercialização da produção; utilização de equipamentos de proteção contra defensivos agrícolas e incidência de contaminação humana; descarte de embalagens de agrotóxicos; infraestrutura existente; fontes de água existentes; lançamento de esgoto; presença de corpos d'água e matas ciliares bem como suas condições; caracterização do lixo e sua destinação; importância atribuída à água, solo, matas ciliares, florestas/matas/bosques, animais silvestres e pássaros e peixes; e por fim o tipo de assistência técnica prestada na propriedade.

Foram entrevistados 21 produtores rurais, de propriedades localizadas no Assentamento Celso Furtado e no Reassentamento Projeto Jupiá. Os aspectos abordados no presente trabalho foram os referentes à destinação do lixo doméstico e o descarte de embalagens de agrotóxicos utilizados. Posteriormente, por meio da análise de dados disposta em gráficos, procurou-se avaliar e caracterizar a disposição final dos resíduos produzidos nas propriedades. 


\section{RESULTADOS}

Com base na análise de dados, relacionou-se o tipo de lixo existente na propriedade com sua destinação. Registrou-se a queima como destinação principal do lixo orgânico (62\%), do papel $(43 \%)$ e do plástico (43\%) nas propriedades visitadas. O principal destino do vidro e dos metais (latas) foi o enterramento no solo (Figura 2).

A queima como o principal destino do lixo doméstico no meio rural tem sido relatada em vários locais como Dobrada (SP) (Américo et al, 2012); Santa Rita do Passa Quatro (SP) (Carvalho et al, 2012) e Assentamento Estrela da Ilha (Ilha Solteira, SP) (Dornfeld et al, 2013).

As práticas de queima e enterramento do lixo são adotadas devido a certa conveniência que trazem aos produtores ao reduzir a quantidade de resíduos e, desse modo, não diminuir ou interferir na área de produção agrícola.

A ausência de coleta seletiva de resíduos como vidro, papel e metais representa um desperdício de recursos naturais e, ao mesmo tempo, favorece práticas poluidoras do ar e do solo, quando esses resíduos são queimados ou enterrados. A prática da compostagem, uma forma racional de reciclagem de resíduos orgânicos com sua transformação em adubo, não foi relatada nas propriedades visitadas. 


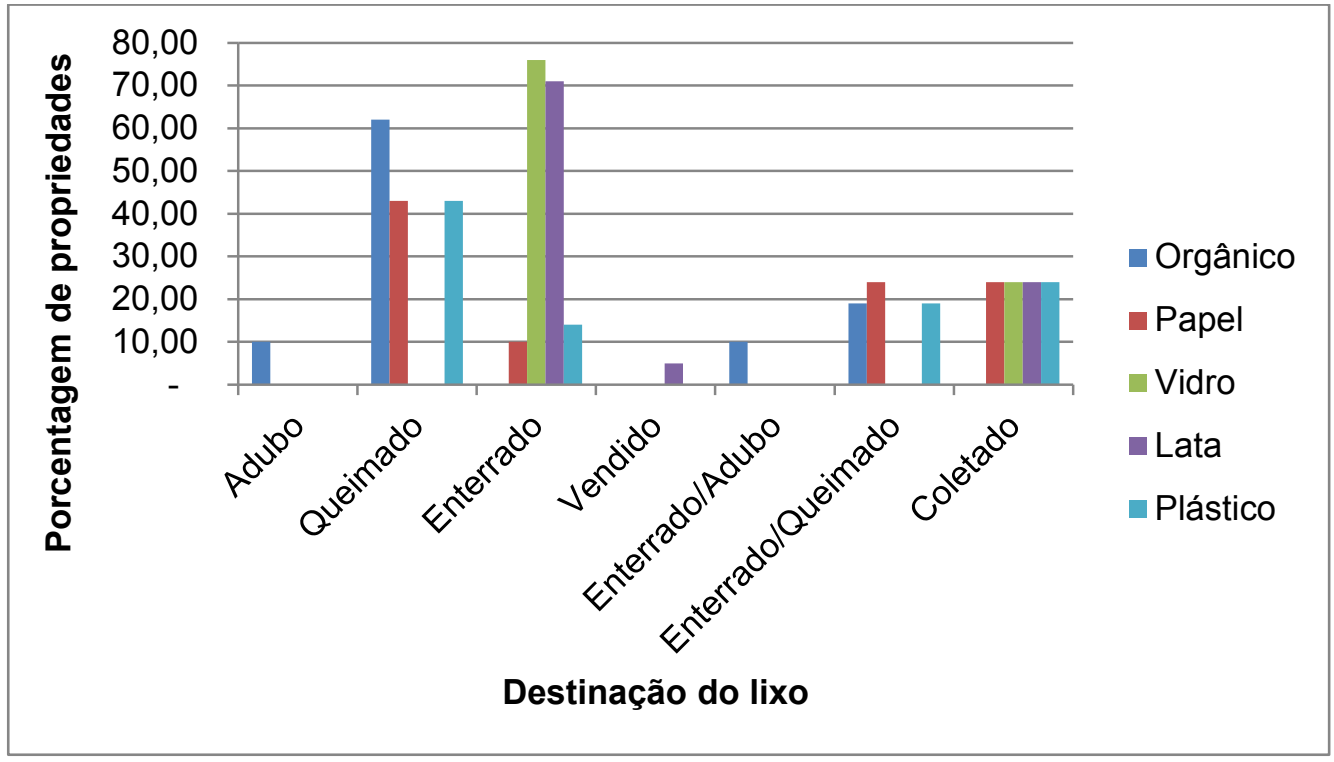

Figura 2. Destinação do lixo doméstico nas propriedades visitadas. Castilho-SP, 2014.

Em relação ao descarte de embalagens de agrotóxicos utilizados, a queima foi relatada como principal destino (67\%) nas propriedades visitadas (Figura 3).

No Assentamento Timboré em Castilho (SP), Arruda et al. (2001) relataram que $50 \%$ das embalagens eram abandonadas ao ar livre, enquanto $70 \%$ dos proprietários reaproveitavam as embalagens para uso doméstico.

Carvalho et al. (2012) observaram no município de Santa Rita do Passa Quatro, que o enterramento era o principal destino das embalagens de defensivos agrícolas, existindo ainda a reutilização das mesmas.

De acordo com os dados obtidos no presente trabalho, não se observou reutilização das embalagens de agrotóxicos, sendo um fator positivo, pois esta prática favorece a contaminação dos indivíduos. 


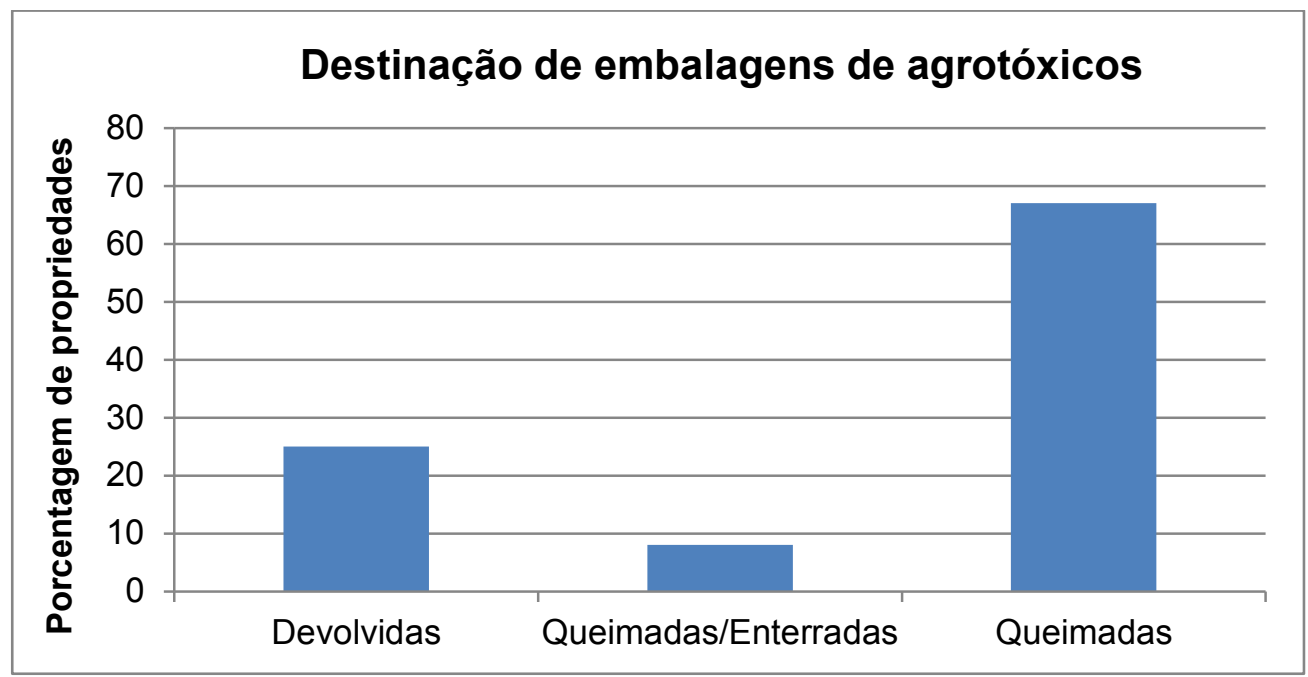

Figura 3. Destinação das embalagens de agrotóxicos nas propriedades visitadas.

Castilho-SP, 2014.

\section{CONSIDERAÇÕES FINAIS}

Segundo a avaliação da destinação do lixo doméstico e agrícola nas propriedades rurais, vê-se a necessidade da implantação de programas de educação ambiental nestas áreas, que pudessem levar ao equilíbrio do uso dos recursos e cuidados com o meio ambiente. Uma vez que os produtores relataram práticas inadequadas de gerenciamento de resíduos, a promoção de conhecimento nestas áreas seria indispensável para modificar os quadros de destinação de resíduos abordados, além de estimular o desenvolvimento sustentável.

Além disso, a disposição de um serviço eficiente de coleta de resíduos por parte do poder público seria imprescindível à proteção do meio ambiente, por diminuir os riscos da poluição, e aos produtores, que não teriam assim, seus resíduos acumulados em suas propriedades.

\section{REFERÊNCIAS}

AMÉRICO, J.H.P.; CARVALHO, S.L.; GONZAGA, M.L.; FREITAS LIMA, E.A.C.; ARAÚJO, C.A.M. Condições Ambientais de Propriedades Agrícolas e Percepção Ambiental de Produtores Rurais do Município de Dobrada- São Paulo, Brasil. In: Holos Environment, v. 12, n.2, 2012p.249.

ARRUDA, S.A. CARVALHO, S.L.; FREITAS LIMA, E.A.C.; ARAÚJO, C.A.M. Percepção ambiental de produtores rurais e das condições ambientais de seus lotes agrícolas no Assentamento 
Timboré em Castilho-SP. In: III Encontro Sobre Educação Ambiental na Agricultura. Campinas-SP, 2001.

CÂMARA MUNICIPAL DE CASTILHO. Disponível em <http://camaracastilho.sp.gov.br>. Acesso em: 7 set. 2014.

CARVALHO, S. L.; ALMEIDA, F.; FREITAS LIMA, E. A. C. Avaliação das Condições SócioEconômico-Ambientais de Algumas Propriedades Agrícolas no Município de Santa Rita do Passa Quatro SP. In: Fórum Ambiental da Alta Paulista, v. 8, n.2, p.348-359, 2012.

CIDADES. Disponível em <http://cidades.ibge.gov.br>. Acesso em: 7 set. 2014.

CITY BRAZIL. Disponível em <http://www.citybrazil.com.br/sp/castilho/dados-gerais>. Acesso em: 7 set. 2014.

DORNFELD, C. B.; LEITE, M. A.; FREITAS LIMA, E. A. C.; SIMONATO, D. C. Saneamento básico em dois projetos de assentamento rural no Oeste Paulista. In: ESADR 2013 - Economia, Sociologia, Ambiente e Desenvolvimento Rural, 2013, Évora - Portugal. ESADR 2013 - Proceedings - C 07 Ambiente e Recursos Naturais. p.1752 - 1769.

MACHADO, A.B.M. Conservação da Natureza e Educação. Silvicultura em São Paulo, v. 16, n.1, p.109-118, 1982.

MARTINS, M. Avaliação das condições sócio-economico-ambientais de algumas propriedades agrícolas no município de Ilha Solteira- São Paulo. Monografia apresentada ao Curso de Agronomia da Faculdade de Engenharia Campus de Ilha Solteira-São Paulo. 2005.

PHILIPPI JR; MALHEIROS, T.F; Saúde ambiental e Desenvolvimento p.63-4. In: Educação Ambiental e Sustentabilidade. Barueri, Ed. Manole, 2011, 878 p. 